\title{
P-band polarimetric ice sounder: concept and first results
}

Dall, Jørgen; Hernández, Carlos Cilla; Kristensen, Steen Savstrup; Krozer, Viktor; Kusk, Anders; Vidkjær, Jens; Balling, Jan E.; Skou, Niels; Søbjærg, Sten Schmidl; Christensen, Erik Lintz

Published in:

IEEE International Geoscience \& Remote Sensing Symposium

Link to article, DOI:

10.1109/IGARSS.2008.4779766

Publication date:

2008

Document Version

Publisher's PDF, also known as Version of record

Link back to DTU Orbit

Citation (APA):

Dall, J., Hernández, C. C., Kristensen, S. S., Krozer, V., Kusk, A., Vidkjær, J., Balling, J. E., Skou, N., Søbjærg, S. S., \& Christensen, E. L. (2008). P-band polarimetric ice sounder: concept and first results. In IEEE International Geoscience \& Remote Sensing Symposium (Vol. Volume 4, pp. 494-497). IEEE.

https://doi.org/10.1109/IGARSS.2008.4779766

\section{General rights}

Copyright and moral rights for the publications made accessible in the public portal are retained by the authors and/or other copyright owners and it is a condition of accessing publications that users recognise and abide by the legal requirements associated with these rights.

- Users may download and print one copy of any publication from the public portal for the purpose of private study or research.

- You may not further distribute the material or use it for any profit-making activity or commercial gain

- You may freely distribute the URL identifying the publication in the public portal 


\title{
P-BAND POLARIMETRIC ICE SOUNDER: CONCEPT AND FIRST RESULTS
}

\author{
Jørgen Dall, Carlos Cilla Hernández, Steen Savstrup Kristensen, Viktor Krozer, Anders Kusk, \\ Jens Vidkjoer, Jan Balling, Niels Skou, Sten Schmidl Søbjerg, and Erik Lintz Christensen
}

Technical University of Denmark

Ørsteds Plads 348, DK-2800 Kongens Lyngby, Denmark, email: jd@space.dtu.dk

\begin{abstract}
ESA has assigned the Technical University of Denmark to develop an airborne P-band ice sounding radar demonstrator. ${ }^{1}$ The intention is to obtain a better understanding of the electromagnetic properties of the Antarctic ice sheet at P-band and to test novel ice sounding techniques in preparation for a potential spaceborne ice sounding radar. The airborne system is a coherent, high-resolution and fully polarimetric radar. Aperture synthesis is applied in the along track direction and an experimental surface clutter suppression technique based on a multi-aperture antenna can be applied in the across track direction. In May 2008, a proof-of-concept campaign was organized in Greenland, where data were acquired over the ice sheet. The system proved capable of detecting the bedrock under $3 \mathrm{~km}$ thick ice and of mapping the internal ice layers down to a depth of at least $1.3 \mathrm{~km}$. In this paper, the system concept is outlined and first results are presented.
\end{abstract}

Index Terms - Polarimetry, clutter, internal layers.

\section{INTRODUCTION}

A spaceborne P-band ice sounding radar has been proposed as a possible Earth Explorer mission. However, the properties of the Antarctic ice sheet at P-band are not sufficiently well known, and the surface clutter suppression techniques required for spaceborne ice sounding have not yet been tested in practice. Therefore, the European Space Agency (ESA) has assigned the Technical University of Denmark (DTU) to develop an airborne P-band ice sounding

Table 1. Ice sounder specifications

\begin{tabular}{lr}
\hline Center frequency & $435 \mathrm{MHz}$ \\
Bandwidth (goal) & $85 \mathrm{MHz}$ \\
Polarization & quad \\
Pulse length & $33 \mathrm{~ns}-50 \mu \mathrm{s}$ \\
Peak power & $100 \mathrm{~W}$ \\
Maximum PRF & $20 \mathrm{kHz}$ \\
Operating altitude & $3500 \mathrm{~m}$ \\
\hline
\end{tabular}

${ }^{1}$ The work is supported by the European Space Agency. radar demonstrator [1]. The development of this ice sounder includes system analysis, design, implementation, aircraft installation, and a proof-of-concept campaign over an appropriate ice sheet in Greenland.

This paper outlines the capabilities of the ice sounder and presents first results. The subsystems have been developed [2], [3], [4] and integrated. In March 2008 the system was installed on a Twin Otter aircraft (Figure 1), certified and functionally tested in Greenland. During the proof-ofconcept campaign in May 2008, data were acquired over the ice sheet in Greenland.

Key parameters are listed in Table 1, and the system

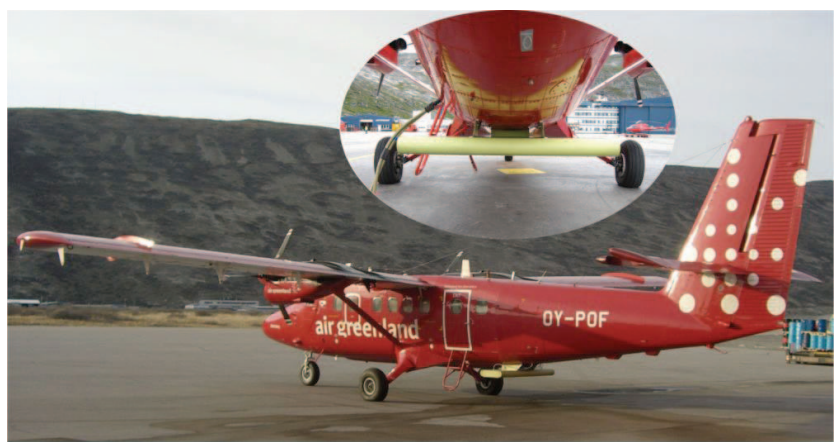

(a)

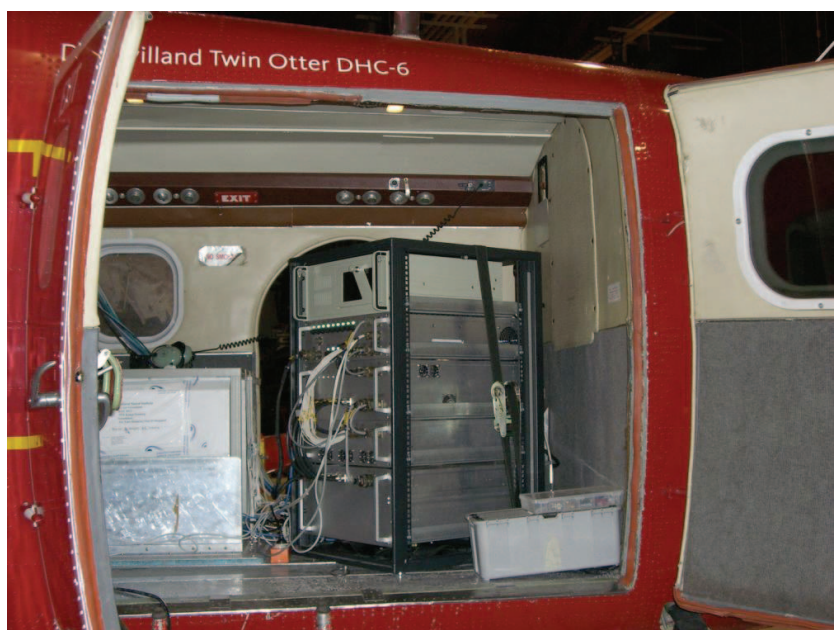

(b)

Figure 1. Installation of antenna (a) and electronics (b). 


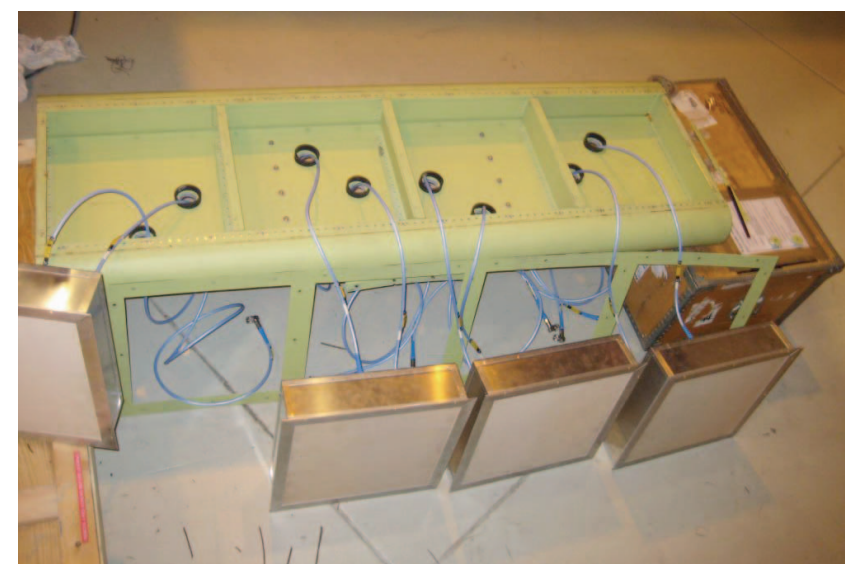

Figure 2. Four-element dual linear polarized antenna.

capabilities requested by ESA include [5]:

- sufficient sensitivity to detect the bedrock in Antarctica through $4 \mathrm{~km}$ of ice and to detect deep ice layers

- sufficient surface clutter suppression for detection of shallow ice layers

- sufficient dynamic range for simultaneous shallow and deep sounding

- a polarimetric capability enabling ice anisotropy (crystal orientation fabric, COF) to be measured

- an experimental clutter suppression capability based on a multi-aperture antenna.

These capabilities are addressed in the following sections. Next, a few campaign results are presented.

\section{SENSITIVITY}

The ice sheet in Greenland is not sufficiently deep to verify the requested penetration depth of $4 \mathrm{~km}$, but according to ice models [6] $2.5 \mathrm{~km}$ of warm ice in Greenland is comparable to $4 \mathrm{~km}$ of cold ice in Antarctica. A high sensitivity is obtained by using a four-element antenna (Figure 2), long frequency modulated pulses (up to $50 \mu \mathrm{s}$ ), and a high pulse repetition frequency (up to $20 \mathrm{kHz}$ ) in combination with along track pre-filtering. A $100 \mathrm{~W}$ solid-state power amplifier suffices. Hitherto, the VHF band $(60 \mathrm{MHz}$ or 150 $\mathrm{MHz}$ ) has primarily been used for ice sounding, but a potential space-based system must operate in the $6 \mathrm{MHz}$ radar band recently allocated at $435 \mathrm{MHz}$ (P-band). This frequency leads to substantially more volume scattering in case the ice is crevassed or the firn includes refrozen ice bodies (ice lenses, ice pipes and ice layers).

\section{SURFACE CLUTTER SUPPRESSION}

Near-surface ice layers may be masked by off-nadir surface signals and by range sidelobes from the nadir surface signal, which is much stronger than the signal from the internal layers. The P-band ice sounder suppresses off-nadir clutter by minimizing the footprint in the along-track direction
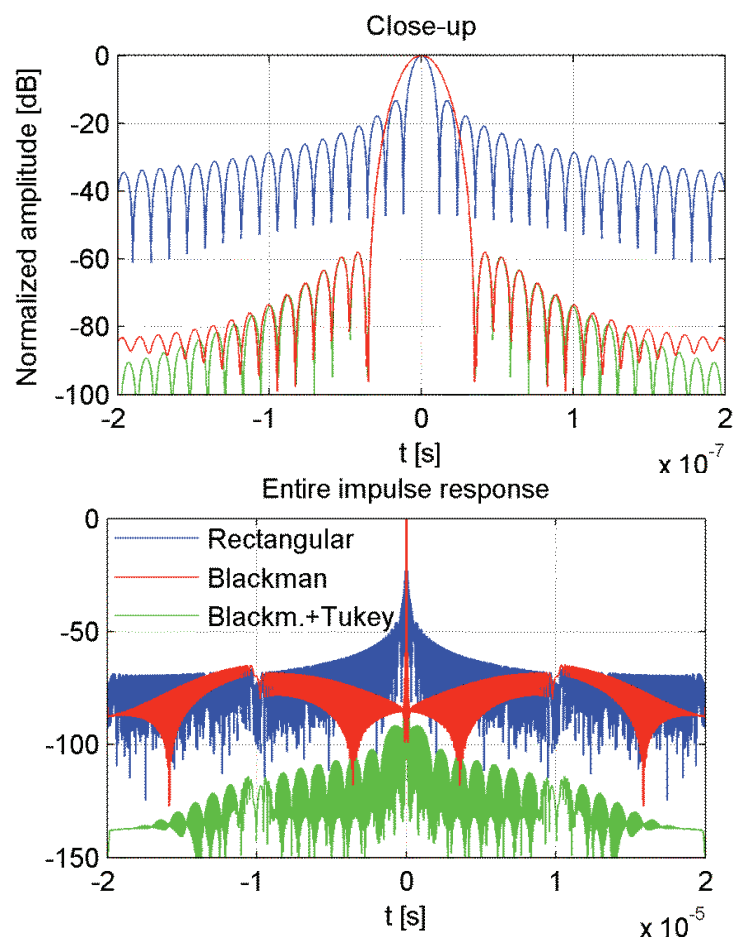

Figure 3. Normalized impulse responses for a $20 \mu$ s pulse with an $85 \mathrm{MHz}$ bandwidth. Blue: rectangular pulse and matched filter. Red: rectangular pulse and Blackmanweighted filter. Green: $2 \%$ Tukey-weighted pulse (timedomain) and Blackman-weighted filter.

(using Doppler processing) and in the across-track direction (using the $1.8 \mathrm{~m}$ wide antenna shown in Figures 1 and 2).

Close-in sidelobes are reduced with conventional spectral weighting, while distant sidelobes are suppressed with a slight amplitude weighting of the transmit pulse [7], e.g. the $2 \%$ Tukey window applied in Figure 3.

\section{DYNAMIC RANGE}

Signals reflected from a smooth air/ice surface are very strong, while signals attenuated by propagation through an ice sheet and back from the bedrock are very weak. Hence, simultaneous shallow and deep sounding may call for a dynamic range exceeding $100 \mathrm{~dB}$, which is more than $\mathrm{A} / \mathrm{D}$ converters with the desired $85 \mathrm{MHz}$ bandwidth can offer. Therefore, a shallow/deep sounding approach is adopted, i.e. when necessary, overlapped near-surface and near-bottom windows are covered separately. This is done simultaneously by alternating the receiver gain on a pulse-by-pulse basis.

Shallow/deep sounding enables short and long pulses to be transmitted alternately. The signal-to-noise ratio (SNR) of the weak signals from the bedrock and from deep internal layers can be improved using a long pulse. However, using a long pulse for shallow sounding would either require simultaneous transmission and reception, and hence an extremely good isolation between the transmit and receive 


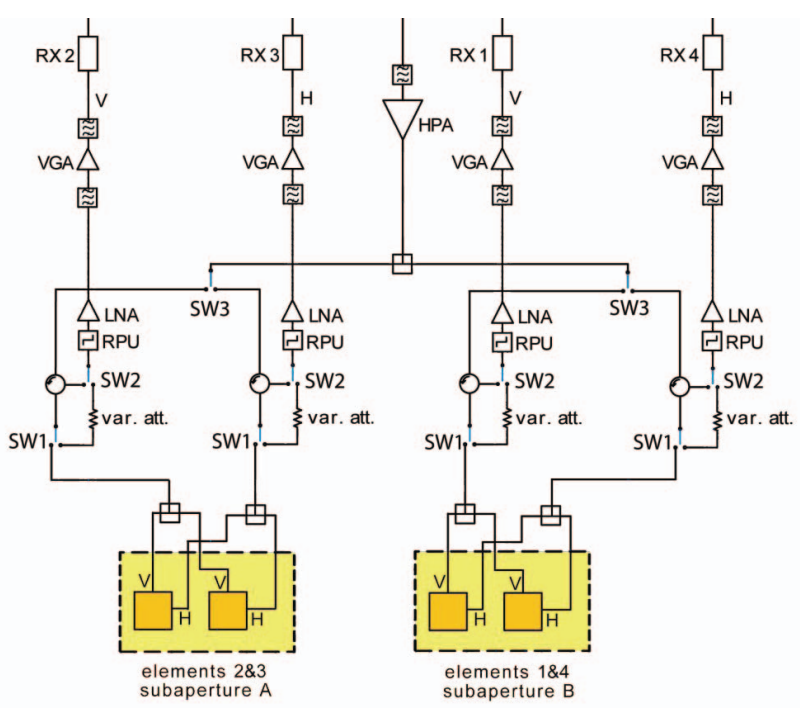

Figure 4. RF architecture. The antenna end elements are shown next to one another in order to simplify the figure.

channels, or it would require the system to be flown high over the ice surface, which in turn has an adverse impact on the power budget and clutter suppression of an airborne system. Consequently, for shallow sounding, short pulses are necessary, but also sufficient to ensure a good SNR.

\section{POLARIMETRY}

Polarimetry offers additional information about the basal condition of the ice sheet and about the internal layers. The strain history of the ice, which is of great interest to glaciologists, impacts the ice crystal orientation, and the resulting birefringence can be detected with polarimetry [8]. Also, abrupt COF changes result in polarization dependent reflections. The variation in echo strength with polarization can exceed $20 \mathrm{~dB}$ [9]. Therefore, the P-Sounder is designed as a fully polarimetric system, allowing any polarization to be synthesized from quad-linear polarized data.

The left (or right) part of Figure 4 shows that the polarimetric capability is implemented the conventional way: A polarization switch (SW3) enables the pulse from the high power amplifier (HPA) to be transmitted alternately on horizontal $(\mathrm{H})$ and vertical $(\mathrm{V})$ polarization, while $\mathrm{H}$ and $\mathrm{V}$ polarization can be received simultaneously.

Polarization synthesis requires a low cross-polarization level and a good channel balance (amplitude and phase). The former is ensured with well designed antenna elements and a proper choice of feed points (Figure 2). The latter is ensured with internal calibration loops (Figure 4) and an accurate thermal stabilization, which is also important in to meet the required $2 \mathrm{~dB}$ absolute calibration accuracy.

\section{MULTI-APERTURE CLUTTER SUPPRESSION}

For a low-flying airborne ice sounder, only the near-surface internal layers are masked by surface clutter, as the ranges

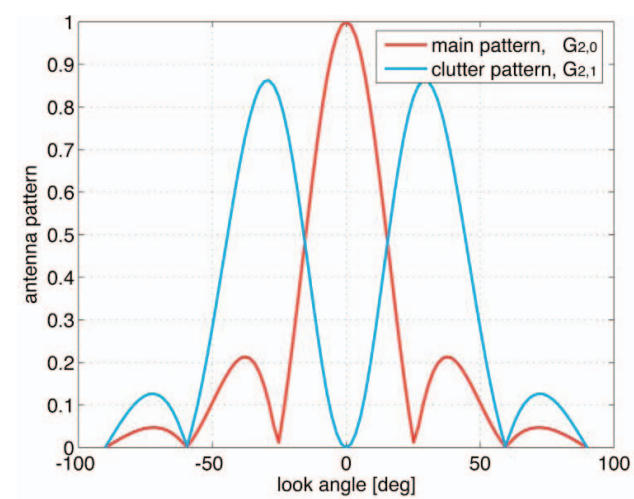

Figure 5. Theoretical radiation patterns of sub-aperture $\mathrm{A}+\mathrm{B}$ (red) and A-B (cyan).

of deeper layers correspond to surface points with large offnadir angles, such that the clutter can be suppressed with the antenna pattern (across track) or with Doppler filtering (along track). However, a spaceborne ice sounder calls for additional clutter suppression in the across track direction.

The P-band sounder features an experimental, coherent clutter suppression technique based on a multi-aperture antenna [10]. In its simplest form, two sub-apertures are formed on the receive side: Sub-aperture A comprises the two middle antenna elements and sub-aperture B comprises the two end elements. The P-band sounder can acquire the A- and B-signals separately as shown in Figure 4. The sum of the two signals equals the signal from the full-aperture antenna, while the difference forms an antenna with a null in the nadir direction. The latter is a clutter-only signal, which can be multiplied by a range dependent scaling factor and subtracted from the full-aperture signal to suppress the clutter contribution. This technique requires a low mutual coupling between the antenna elements, and this is obtained by using cavity-backed elements as shown in Figure 2.

The simple two-aperture configuration assumes left/right symmetry. However, the P-band sounder also supports a (single-polarization) four-aperture configuration, which is applicable in case of surface slopes.

\section{FIRST RESULTS}

The proof-of-concept campaign included calibration and clutter suppression experiments, but most importantly a track from Kangerlussuaq to the ice divide in the dry snow zone at $38^{\circ} \mathrm{W}, 69.5^{\circ} \mathrm{N}$. ESA's main interest is the Antarctic ice sheet, which is almost entirely located in the dry snow zone, and near the ice divide the ice flows primarily perpendicular to the ice ridge, which results in a COF that can be used to test the polarimetric capability.

Figure 6 shows internal layers near the ice divide. The flight altitude was $2000 \mathrm{ft}$, and he bright line at the top is the surface echo. The double bounce echo from the surface is seen at a depth of $350 \mathrm{~m}$, and at about $750 \mathrm{~m}$ the seem between the shallow and the deep window can be seen (especially in the blow up) because the resolution happens 


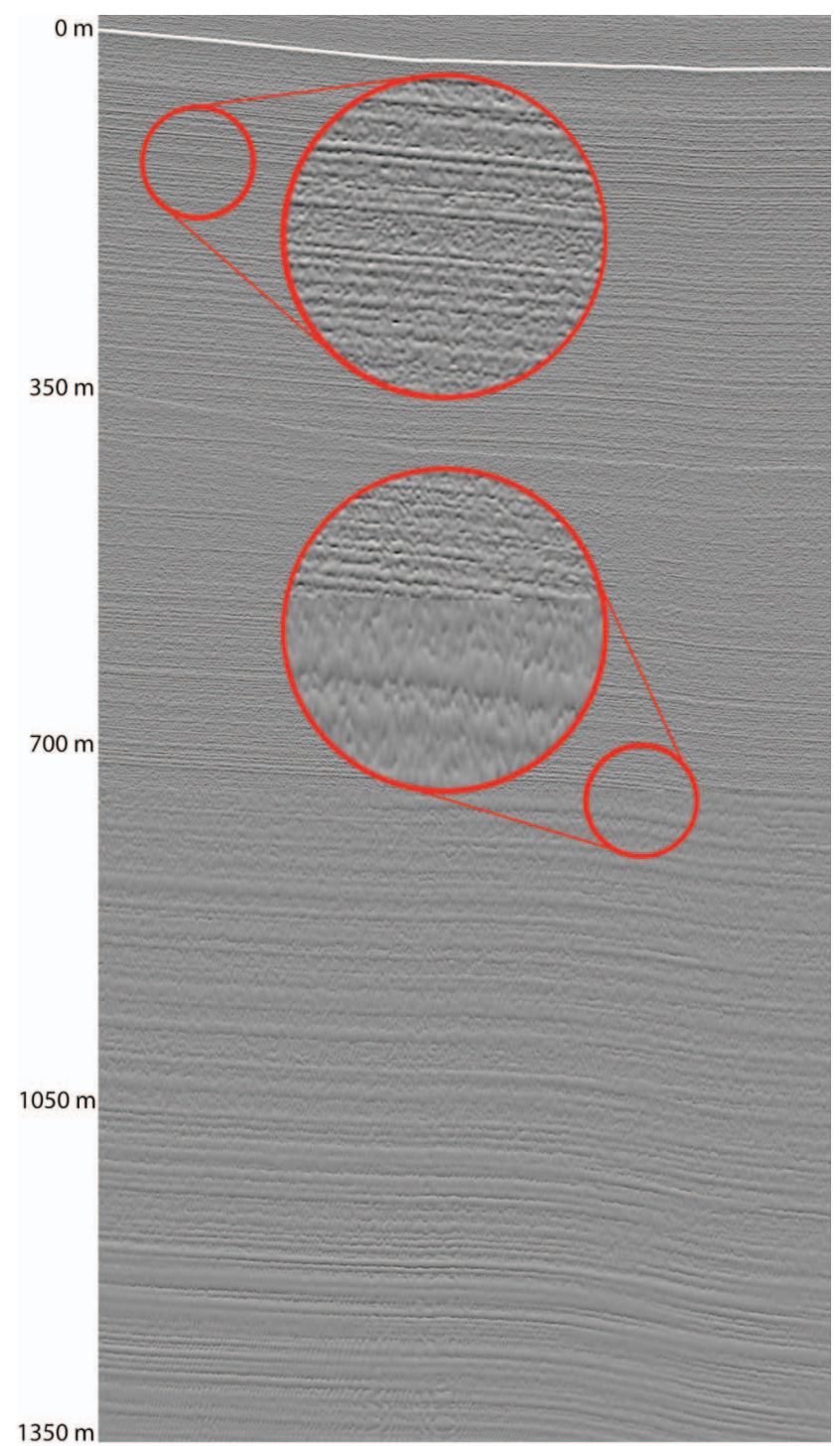

Figure 6. Internal ice layers mapped in shallow/deep mode.

to differ. A $2 \mu \mathrm{s}, 85 \mathrm{MHz}$ pulse was used for the shallow window and a $10 \mu \mathrm{s}, 30 \mathrm{MHz}$ pulse for the deep window.

Figure 7 shows the bedrock detected through almost $3 \mathrm{~km}$ of ice. The data were acquired from an altitude of $1000 \mathrm{ft}$ over the ice surface, using a $30 \mu$ s long pulse with a bandwidth of $6 \mathrm{MHz}$. In the along track direction, data have been focused with the PDP algorithm [11].

\section{CONCLUSIONS}

DTU has built and tested an airborne P-band ice sounder for ESA. The system has been flown in Greenland, and the first results suggest that it is possible to detect the bedrock and to map deep ice layers in Greenland at P-band. Fully polarimetric data and multi-aperture data intended for clutter suppression have been acquired but yet processed.

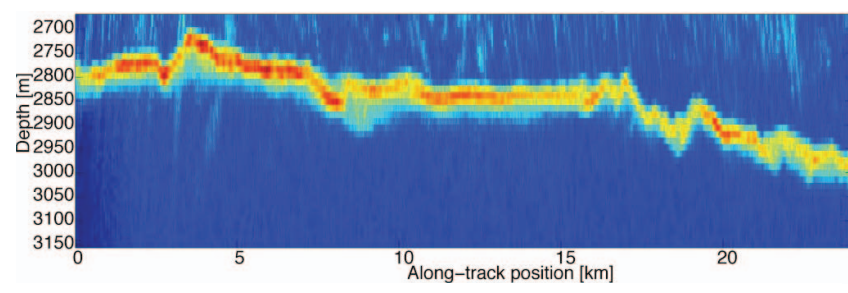

Figure 7. Bedrock near the ice divide.

\section{REFERENCES}

[1] C.-C. Lin, F. Hélière, P. Bensi, A. Thompson, M. Aguirre, C. Buck, M. Ludwig, M. Süss, N. Le Gallou, M. Aloisio, C. Mangenot, K. van't Klooster, P. Rinous, J.S. Prowald, B. Rommen, N. Floury, A. Wielders, "ESA's SAR technology and future mission concept developments beyond Sentinel-1", Proc. of EUSAR 2008, Vol. 2, pp. 123-126 Friedrichshafen, June 2008.

[2] J. Dall, N. Skou, A. Kusk, S.S. Kristensen, V. Krozer, "Psounder: an airborne P-band ice sounding radar", Proc. of the IEEE 2007 International Geoscience and Remote Sensing Symposium, Barcelona, 4 p., July 2007.

[3] V. Krozer, C.C. Hernandez, J.L. Vazquez Roy, J. Vidkjær, and J. Dall, "Development of an airborne ice sounding radar", Proc. of the European Microwave Week, Munich, 4 p., October, 2007.

[4] J. Dall, S.S Kristensen, V. Krozer, C.C. Hernández, J. Vidkjær, A. Kusk, J. Balling, N. Skou, S.S. Søbjærg, E.L. Christensen, "Implementation of an airborne P-band ice sounding radar", Proc. EUSAR 2008, Vol. 2, pp. 103-106 Friedrichshafen, June 2008.

[5] "Annex 1 to P-Band Ice Sounding Radar Demonstrator Development; Technical Specifications", ESTEC TECETP/2004.31, version 2, November 2004.

[6] "Annex 2 to P-Band Ice Sounding Radar Demonstrator Development, A simplified scattering model", ESTEC TECETP/2004.31, version 2, November 2004.

[7] T.X. Misaridis and J.A. Jensen, "An effective coded excitation scheme based on a predistorted FM signal and an optimized digital filter", Proceedings of IEEE International Ultrasonics Symposium, pp. 1589-1593, 1999.

[8] S. Fujita, H. Maeno, K. Matsuoka, "Radio-wave depolarization and scattering within ice sheets: a matrix-based model to link radar and ice-core meawurements and its applications", Journal of Glaciology, Vol. 52, No. 178, pp. 407-424, 2006.

[9] Doake, C.S.M., Corr, H.F.J., and Jenkins, A., "Polarization of radio waves transmitted through Antarctic ice shelves", Annals of Glaciology, 34, pp. 165-170, 2002.

[10] B. Rommen, C.C. Lin, J. Guijarro and B. Ramirez Valado, "Scientific rationale for a spaceborne P-band Ice-Sounder", Open Science Conf./XXVIII SCAR/COMNAP VVI, Antarctica and the Southern Ocean in the Global Systems, Bremen, July 2004.

[11] R.K. Raney, B.L. Gotwols, and J.R. Jensen, "Optimal Processing of Radar Ice Sounding Data", Proc IGARSS'99, pp. 1999. 